\title{
Design on the System of Aviation Equipment Support and Command
}

\author{
Liming Wang ${ }^{1, a, *}$, Shuli Yuan ${ }^{2, \mathrm{~b}}$ Huayuan Zhu ${ }^{1, \mathrm{c},}$ Yunfei Ji ${ }^{1, \mathrm{~d}}$ and Lingzhi Wang ${ }^{1, \mathrm{e}}$ \\ ${ }^{1}$ Qingdao Brangch of Naval Aeronautical and Astronautical University,Qingdao 266041,China; \\ ${ }^{2}$ Qingdao Agricultural University, Qingdao 266109,China;

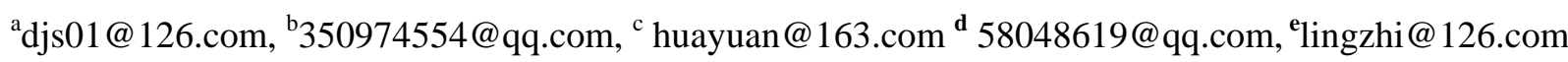

Keywords: Equipment Support, Command, Model Architecture.

\begin{abstract}
In order to improve the ability of the aviation equipment support commanders, the system of aviation equipment support and command is designed. Setting goals and principles, the content composition and construction scheme of the system are studied and designed from the hardware and the software. The system can provide the method and reference for the training of the aviation equipment support commanders.
\end{abstract}

\section{Introduction}

The system of aviation equipment support and command is mainly to combat flight support, combat readiness level conversion, aircraft battle damage repair and other typical aviation of equipment support. It master the command contents, procedures and methods of wartime equipment support, and improve "the ability of equipment support and command ","the ability of equipment management" and "the ability of leadership" for the aviation equipment support commanders.

\section{Objectives and Principles}

The system of aviation equipment support and command is based on the reform and innovation of military training under the condition of information, focus on the command of typical tasks aviation equipment support, following the goal and principle of construction:

\subsection{Objective of Construction}

Build a system of aviation equipment support and command for operational and tactical levels, and provide practical environment for the optimization of aviation equipment support and command.

\subsection{Principle of Construction}

Construction of the system should follow the unified national military standard and standard. First, the principle of progressiveness and stability. The system should achieve scientific structure, reasonable function, and the equipment and technology should be advanced and reliable. The main network system has good compatibility, good maintainability and low maintenance cost. Second, the principle of practicability and extensibility. The system should select the corresponding performance level products to meet the needs of practical work and research. At the same time, give full consideration to improve and expand for the future integrated command system. Third, the principle of consistency and safety. The system should be in accordance with the idea of "scientific construction and standardized management", strictly abide by the relevant state network construction of the relevant standards and regulations, technology and equipment must comply with the requirements of national standard, the network system is not only to achieve good interoperability, but also have good safety. 


\section{Function}

The first is the command function of aviation equipment support. The system focus on the command of the combat flight support and mobility transitions by the situational simulation system of aviation equipment support and command, the decision support system of aviation equipment support and command, and the model of combat flight support and mobility transitions. The second is the planning of aviation equipment support. Draft the report and advice solution plan of aviation equipment support for air regiment and air base. Three is the control of aviation equipment. Control the aviation equipment for combat flight support and mobility transitions. Fourth, optimal allocation of resources. Through the model of combat flight support and mobile transit, Optimal the air material support and other support resources. Fifth, the special disposition function. Conduct the special handling by the situation simulation system of aviation equipment support and command.

\section{Composition}

The system of aviation equipment support and command should be composed of command centers, air command divisions, air stations, command rooms, equipment rooms and so on. Set up a number of command stations for air regiment and air base, and configure the software system of aviation equipment support and command.

\subsection{Hardware}

The hardware of the aviation equipment support and command mainly includes: first, the network is composed of a group of integration platform, the core server message server, database server, some business platform, and telephone systems. Two is the system of audio and video. The system based on telephone, projection system, LED electronic screen and video surveillance. Three is the command station.

\subsection{Software}

The software of aviation equipment support and command mainly includes: one is the typical mission model of aviation equipment support. Mainly including the model of command configuration and the relation for air regiment and air base, the information interaction model of command process, the calculation model of support requirements, etc. It is used for the analysis of decision-making and optimization plan in the preparation and promotion. The second is the decision of aviation equipment support and command. The system is consists of the support information subsystems, personnel support, equipment support, spare parts supply chain, and the airport foundation information database, demand measuring support subsystem, support scheme of artificial subsystem, evaluation subsystem, etc. Three is the simulation system of aviation equipment support and command. The system consists of 3d digital simulation airports, aircraft, and safeguard equipment, etc.

\section{Construction Plan}

\subsection{Hardware Construction}

The system of aviation equipment support and command should make full use of the integrated command platform, and the telephone network should be realized by the configuration of the multifunctional node interactive machine. In the management system of audio and video, both the pilot seat and the command position node should be regarded as the equivalent audio/video application node, and each node is defined as a relatively independent domain, and the sound/video device in the domain can only be managed by its own console and the total console in its domain through the corresponding software.

\subsection{Software Construction}

\subsubsection{The Decision Support System of Aviation Equipment Support and Command}

The decision support system of aviation equipment support and command should be composed of the support information subsystem about the aviation equipment, personnel support, equipment support, airport, etc. the support program subsystems of the combat readiness level, operation, 
maneuver, repair, rescue, protection and other protection programs, and the integrated evaluation subsystem of the evaluation criterion base and comprehensive evaluation operation model.

The system can be divided into user authentication, business management and database. The database is divided into two parts of support information database and file database. The system should be designed as a C/S structure framework, which can be adopted the technology of Net 2.0 (.net FrameWork2.0); The backend database can be used for SQLServer2005, and the access to the data is primarily stored procedures; The programming language can be Visual c \#, and the development environment can be Microsoft Visual Studio 2005.

\subsubsection{The Simulation System of Aviation Equipment Support and Command}

The simulation system of aviation equipment support and command should be composed of three-dimensional digital simulation model(airport, aircraft and support equipment, etc.) the demonstration module of support project (electrify, refueling, hanging bombs, etc.), the simulation module of the special situation (runway, etc.), and the control System. The simulation system should have the function of the dispatching situation demonstration about airplane and each kind of support vehicle in the airport, the process demonstration about support work item (refueling, electrify etc.), holds the virtual meeting and so on.

Simulation Airport is realized by virtual reality technology, using the Vega Prime as the display platform of the virtual scene, the animation flow is used to show the realization of the key node action, using GL studio as the virtual interactive and virtual instrument control platform, using the VB. NET as the system integration tool, and realize equipment simulation and process simulation by the technology of VC. NET.

Simulation of aircraft and support equipment, action control simulations are implemented by VC language programming. The scene drive and simulation module, which is integrated and compiled through the.net environment, the final generation of the release executable file for equipment Support command.

The system of command and control is used for process control and situation setting, and the console software is realized by the interface form of two-dimensional airport electronic map. Airport two-dimensional electronic map, through the geographical information editing software implementation, command control using VC. NET component implementation, The system integration is used of VB. NET language.

\section{Conclusions}

Analysis on the goal and the principle of the system to improve the ability for the aviation equipment support commanders. The construction project has important guiding significance and practical application value for training the formation of "equipment command ability", "equipment management ability" and "leadership management ability" of aviation equipment support commanders.

\section{References}

[1] Hai Huang, Junhai Cao, Zhiwei Shan. Design of the MAS-based Mnterial Integrated Support Simulation System, J. Journal of Naval University of Engineering, 03 (2008) 17-21.

[2] Yingwu Peng, Qingmin Li, Rui Wang, Dejun Mao. Analysis and application of equipment support simulation model architecture, J.Journal of Naval University of Engineering, 05 (2010)62-68.

[3] Xuan Bao, Huijun Gao. Evaluation Model for Equipment Support and Command System's Organizational Structure, J .Ordnance Industry Automation. 05 (2009) 57-59. 